\title{
The importance of enhancing, maintaining and saving face in smartphone repurchase intentions of Chinese early adopters: an exploratory study
}

\begin{abstract}
Purpose - China is the world's largest consumer market for smartphones. Early adopters are highly influential in consumers' decisions of new technologies. Therefore, understanding Chinese early adopters' decision making in the smartphone market is of crucial importance to smartphone companies. There is a dearth of in-depth studies on the factors affecting consumers' repurchase intention for smartphones. The aim of our study is thus to narrow this knowledge gap by developing a new conceptual framework explaining early adopters' repurchase intention of smartphones.

Design/methodology/approach - Using 30 face-to-face interviews with Chinese early adopters of smartphones, we built a new theoretical framework to explain the factors that influence their repurchase intention.
\end{abstract}

Findings - Repurchase intention of smartphones is determined by aesthetic and utilitarian product-related factors (design appeal, perceived usefulness), socio-cultural factors (subjective norms, mianzi/face considerations), and brand-related factors (brand popularity, brand's country-of-origin, perceived brand quality, and brand loyalty). The emerging framework also explores the factors affecting enhancing, maintaining and saving mianzi/face.

Originality/value - In contrast to existing technology-driven models, the study’s emerging framework shows how aesthetic, socio-cultural and brand-related factors can offer new insights in understanding repurchase intention in a rapidly developing market. As these factors are rarely examined in the information technology and/or marketing literatures, potential knowledge contribution can be highly expected.

Paper Type - Empirical paper 
Keywords smartphone; Chinese consumers; early adopters; brand influence; socio-cultural influence; utilitarian influence; product aesthetics; repurchase intention.

\section{Introduction}

In the twenty-first century, smartphones have been increasingly viewed as a necessity for the majority of consumers across all demographic dimensions (Persaud and Azhar, 2012). A smartphone is an advanced mobile phone that thanks to a larger data storage capacity and improved internet connectivity can integrate the functions of multiple devices such as personal computer (e.g. operating systems), video/photo camera, global positioning system (GPS), and music player. Recently, smartphone penetration rate has exceeded two-thirds of mobile subscribers in the U.S.A. (Nielsen, 2014) while China's smartphone user base has already become the largest in the world with more than one billion users in 2015 (eMarketer, 2015a). In the contemporary business world and society, smartphones have further become a life companion for many consumers who use them multiple times each day to perform a wide range of social, cognitive, and business activities.

Despite the exponential growth of smartphone technology and its rapid adoption by vast numbers of consumers, to date, there is a paucity of in-depth, qualitative research on the factors that influence consumers' decision with regards to smartphones (Koo et al., 2015). In fact, most of existing studies focus on consumer adoption of smartphones (e.g. Park and Chen, 2007; Chen et al., 2009) and there is limited knowledge about the factors that may motivate consumers' repurchase intention of smartphones. In the IS literature repurchase intention is equated to continued use (Bhattacherjee, 2001). Existing empirical research on continuance/repurchase intention is mostly based on quantitative approaches built around technology-driven theories and existing studies have often obtained contrasting and/or inconsistent results. Moreover, no study has adopted a holistic approach in examining the 
phenomenon or carried out an in-depth investigation of the factors leading to repurchase intention, particularly in the context of smartphones. The lack of empirical knowledge in these research areas can be further observed in little understanding of contextual factors, especially in the Chinese context, that influence consumers' repurchase decisions. While contexts have been known to contribute to theorizing the distinct nature of certain consumer phenomena (Kozinets, 2002; Tian and Belk, 2005) and the interaction between underinvestigated consumers and their spatial and temporal conditions (Crockett and Wallendorf, 2004), their potential impacts on Chinese consumers' repurchase decisions for smartphone brands can be rather different from existing knowledge gained from Western societies.

For instance, China is considered a collectivist society (Hofstede, 1984) strongly driven by the teaching of Confucius, a Chinese philosopher, teacher and political figure who lived between 551 and 479 B.C. and whose ideas spread out across China and other Asian countries (Fang, 1999). Many contextual factors like collectivism, group norms and orientation, harmony, and face derive from the Confucius doctrine and might be particularly important in China compared to other contexts such as individualist countries (e.g. US and UK) where individuals' behaviors are primarily driven by personal orientation and goals, self-interest and autonomy. In other words, Chinese consumers' behaviors in general, and repurchase decision in particular, might be less related to individual/personal factors, but more driven by social and cultural constructs such as group orientations or needs to increase their reputation (mianzi) or to save face in front of significant others.

Thus, this study seeks to address these knowledge gaps by developing a new conceptual framework, which will take into account the various factors - including cultural variables that potentially influence Chinese consumers' repurchase intentions of smartphone brands. China is chosen as the context of this study because of its distinct cultural attributes, the sheer 
size of its population, and growing smartphone industry that is already the world's leading smartphone market (eMarketer, 2015b).

Situated in such a unique context, the study has important implications for smartphone managers, marketers, and R\&D professionals in that it offers valuable insights as to how to produce and market conspicuously consumed high-tech products to Chinese consumers and increase their sales.

\section{Literature review}

\subsection{Technology adoption theories}

A smartphone is more than a simple mobile phone as it adds new functionalities such as an operating system (e.g. iOS, Android), internet connectivity, a video and/or photo camera, music players, internet applications, GPS, and a larger data storage capacity. Statistics show that the global diffusion and penetration of smartphone technology is exponential (Nielsen, 2014). The ubiquity, usability, and processing power of smartphones enable consumers to undertake numerous activities on-the-go such as sending and responding to emails, shopping, doing business, networking, socializing, and much more.

Theories like the Technology Acceptance Model (TAM) (Davis, 1989), the Theory of Reasoned Action (TRA) (Fishbein and Ajzen, 1975), the Theory of Planned Behavior (TPB) (Ajzen, 1991), or Innovation Diffusion Theory (IDT) (Rogers, 2003) are some of the most frequently used frameworks to investigate individuals' technology adoption behaviors. The above mentioned technology acceptance theories have also been empirically tested to predict consumer adoption of smartphones (e.g. Park and Chen, 2007; Chen et al., 2009) as summarized in Table 1.

Table 1. Academic literature on smartphone adoption 


\begin{tabular}{|llll|} 
Author & Theory & Context & Findings \\
\hline Park and Chen (2007) & $\begin{array}{l}\text { IDT, TAM, self- } \\
\text { efficacy theory }\end{array}$ & $\begin{array}{l}\text { Healthcare } \\
\text { organizations }\end{array}$ & $\begin{array}{l}\text { Attitude, perceived ease of use, } \\
\text { perceived usefulness, self-efficacy } \\
\text { influenced behavioral intention }\end{array}$ \\
\hline Chen et al. (2009) & IDT and TAM & $\begin{array}{l}\text { Delivery service } \\
\text { company }\end{array}$ & $\begin{array}{l}\text { Self-efficacy and perceived ease of } \\
\text { use influenced behavioral intention } \\
\text { to use the technology }\end{array}$ \\
\hline Joo and Sang (2013) & TAM & $\begin{array}{l}\text { Korean adult } \\
\text { users of } \\
\text { smartphones }\end{array}$ & $\begin{array}{l}\text { Smartphone use was affected more } \\
\text { by motivations based on } \\
\text { instrumental and goal-oriented use } \\
\text { than by ritualized and less-goal } \\
\text { oriented use }\end{array}$ \\
\hline Kim et al. (2014) & $\begin{array}{l}\text { TAM, IDT, } \\
\text { value-added } \\
\text { model, social } \\
\text { influence }\end{array}$ & $\begin{array}{l}\text { American } \\
\text { college students }\end{array}$ & $\begin{array}{l}\text { Perceived ease of use and perceived } \\
\text { usefulness did not affect adoption. } \\
\text { Smartphones seemed to be adopted } \\
\text { more to signal affiliation and timely } \\
\text { technology adoption }\end{array}$ \\
\hline
\end{tabular}

\subsection{Continuance/Repurchase intention theory}

Since the launch of first smartphone models dated back in the early 2000s, many users now own the second and third generation of smartphones. In fact, approximately $24.5 \%$ of the world's population use them (eMarketer, 2015a) and by 2018 the number of smartphone users is predicted to exceed 2.56 billion (eMarketer, 2015b). In light of smartphones' exponential diffusion over time, empirical investigation into the motivations and repurchase intention for smartphones would thus be insightful.

The Information Systems (IS) continuance model was introduced by Bhattacherjee (2001) who adapted the Expectation Confirmation Theory (ECT) from marketing (Oliver, 1980, 1993) to the IS field to explain post-adoption behavior. In the IS literature, repurchase and continuance intentions are used interchangeably "because both decisions (1) follow an initial (acceptance or purchase) decision, (2) are influenced by the initial use (of IS or product) experience, and (3) can potentially lead to ex-post reversal of the initial decision” 
(Bhattacherjee, 2001, p. 355). When a purchase is needed, scholars prefer to use the term repurchase intention instead of continuance intention (e.g. online shopping, mobile services).

Primary constructs in the original ECT consist of expectation, performance, confirmation, satisfaction, and repurchase intention. The theory states that consumers are satisfied when their expectations regarding the product performance at the pre-purchase level are met by their actual experience of using that product in the post-purchase stage of consumer decisionmaking process. Eventually, their decision to repurchase the same product and service is influenced by their level of satisfaction. On the contrary, if the performance of the product or service does not meet their initial expectations, they will be dissatisfied and in turn discontinue using/purchasing the same product or service. Satisfaction or dissatisfaction is thus considered as resulting from the confirmation or disconfirmation of prior expectations regarding product performance and viewed as the main determinant of repurchase intention.

According to Bhattacherjee (2001), the success of IS depends on continued use rather than first-time use and existing acceptance models provide limited explanation of, and may sometimes contradict with, observed continuance behavior. In line with this view, the notion of continuance intention has gained increasing attention in a variety of research contexts such as e-Learning (e.g. Chiu et al., 2007; Roca and Gagné, 2008; Lee, 2010), social networking websites (e.g. Kim, 2011; Basak and Calisir, 2015), Web 2.0 (Chen et al., 2012), blogging (Shiau and Luo, 2013; Tang et al., 2014), instant messaging (Wang et al., 2012), website (Lin et al., 2005), online banking (Bhattacherjee, 2001; Vatanasombut et al., 2008), online communities (Chou et al., 2010), self-service technologies (Chen et al., 2009), and many more (see Table 2). Interestingly, these studies all adopt hypothetic methods where the relationship between various factors and continuance intention was tested.

Unfortunately, inconsistency about significant factors that lead to continuance intention of information technology (IT) usage is commonly found. For example, in the context of instant 
messaging, Wang et al. (2012) find that perceived usefulness and satisfaction lead to continuance intention while perceived enjoyment is not directly linked to continuance intention but to perceived usefulness and satisfaction. By contrast, Chong (2013) notes that perceived enjoyment, along with satisfaction, perceived usefulness, perceived ease of use, trust, and perceived cost, are directly related to Chinese consumers' continuance intention of mobile commerce adoption. Limayem et al. (2007) discover that habit acts as a moderating variable of the relationship between intention and continuance behavior of the World Wide Web. Kim (2011) finds that satisfaction has no significant effects on consumers' continuance intention to use social networking services. As summarized in Table 2, other factors that may contribute to continuance intention in different IT contexts include electronic word-of-mouth, subjective norm, critical mass, procedural fairness, affective commitment, experiential learning, perceived behavior control, concentration, interpersonal influence, media influence, performance expectancy, and user involvement. Most of these factors have been identified in behavioral science literature, mostly emanating from TRA (Fishbein and Ajzen, 1975) and TPB (Ajzen, 1991) and technology adoption scholarship such as TAM (Davis, 1989) and IDT (Rogers, 2003). Scholarly works in both marketing and IS have benefited from these theories and concepts. However, there remains a paucity of research that attempts to combine marketing and IS literature with a view to obtain a more holistic understanding of continuance/repurchase intentions. Repurchase intentions, for instance, in a market populated by several companies offering similar models of the same technology can also involve evaluations of the price of a product, of its unique features, or of the symbolic meanings and communicative power of brands.

Additionally, cultural factors might be important in the Chinese context. We argue that deeper insights into cultural attributes would potentially contribute to conceptual and theoretical advancements in this area. For instance, the subjective norm (Ajzen, 1991) 
identified in the adoption literature does not fully capture Chinese cultural dynamics and intricacies. Even the application of a popular adoption model such as UTAUT (Unified Theory of Acceptance and Use of Technology) does not produce the same results in Chinese and US contexts due to the uniqueness of social influence in the Chinese context (Venkatesh and Zhang, 2010). More recent literature on adoption of 3G mobile phones among Chinese consumers (Song et al., 2015) also indicate the profound influence of social pressure on individuals' purchase decisions in the Chinese context which reaffirms some of the earlier literature in this area (Lee, 1990).

\subsection{Chinese cultural values}

Chinese cultural values, and in particular Confucianism, have received some research attention in the marketing literature (Yau, 1988; Lee et al., 2001; Leung and Chan, 2003; Le Monkhouse et al., 2012) due to their influence on consumer behavior (Bao et al., 2003). For example, previous research has investigated the importance of face saving in business negotiations (Leung and Chan, 2003), and its influence on purchase intentions for either selfuse or gift giving (Chen and Kim, 2013) as well as on consumer perceptions of luxury goods (Le Monkhouse et al., 2012).

More specifically, the word mianzi shares similar meanings with 'face'. It implies consciousness of glory and shame and represents an individual's reputation and social position in others' eyes (Hu, 1944). Mianzi stands for "the kind of prestige that is emphasized... a reputation achieved through getting on in life, through success and ostentation", while face is "the respect of a group for a man with a good moral reputation: the man who will fulfil his obligations regardless of the hardships involved, who under all circumstances shows himself a decent human being” (Hu, 1944, p. 45). 
Mianzi/Face goes far beyond the concept of subjective norm widely used in explaining human behaviors in response to social influence. It stands for social image one gains through social success and involves a complex package of perceptions and behaviors within Chinese relational settings (King, 1993). In fact, mianzi is a far more complicated concept and it involves fellowship and recognition within a group, endorsement of competencies and skills, emotions and sense of self-esteem (Liao and Bond, 2010; Qi, 2011). Unlike subjective norm, mianzi not only defines one’s image within his or her social group, but also encourages him or her to reciprocate and emulate behavior (Lee et al., 2001). Mianzi can be enhanced, maintained or lost, and the ramifications of losing it could be immense in societies influenced by Confucianism, and potentially lead to rejection/disapproval and damage of one's selfimage.

As such, research has suggested that saving face may have more impact on Chinese consumers than subjective norm (Ji and Kang, 2010). More specifically, the notion of mianzi might have particularly profound implications on Chinese consumers' behaviors because they tend to increase or maintain their reputation in front of socially and culturally significant others on the one hand, and defend or save face on the other.

\subsection{Summary}

The disparities among theories and various factors found in the continuance/repurchase intention literature reflect typical issues of deductive, hypothetic methods where results found are often biased toward the researchers' prior assumptions or specific research interests. Additionally, it is evident that there is a dearth of studies that carry out an in-depth investigation of the factors leading to repurchase intention, particularly in the context of smartphone technology. We thus argue that insights gained through a qualitative approach would be particularly valuable because the investigation is based on consumers' in-depth 
perspectives rather than the researchers' own prior assumptions. A qualitative study might help clarify the often contrasting and/or inconsistent results obtained in previous studies. This calls for a more holistic approach in the study of repurchase intentions that goes beyond the existing understanding of the aforementioned technology-driven models.

Table 2. Academic literature on continuance intention

\begin{tabular}{|c|c|c|}
\hline Author & Technology & $\begin{array}{l}\text { Factors affecting continuance } \\
\text { intention }\end{array}$ \\
\hline Bhattacherjee (2001) & Online banking & $\begin{array}{l}\text { Satisfaction } \\
\text { Perceived usefulness }\end{array}$ \\
\hline Lin et al. (2005) & Website & $\begin{array}{l}\text { Playfulness } \\
\text { Satisfaction } \\
\text { Perceived usefulness }\end{array}$ \\
\hline Roca et al. (2006) & e-Learning & Satisfaction \\
\hline Limayem et al. (2007) & World Wide Web & $\begin{array}{l}\text { Satisfaction } \\
\text { Frequency of past behavior } \\
\text { Comprehensiveness of usage } \\
\text { Habit }\end{array}$ \\
\hline Liao et al. (2007) & e-Service & $\begin{array}{l}\text { Satisfaction } \\
\text { Perceived usefulness } \\
\text { Subjective norm } \\
\text { Perceived behavioral control }\end{array}$ \\
\hline Chiu et al. (2007) & e-Learning & $\begin{array}{l}\text { Satisfaction } \\
\text { Procedural fairness }\end{array}$ \\
\hline Chiu and Wang (2008) & Web-based learning & $\begin{array}{l}\text { Performance expectancy } \\
\text { Effort expectancy } \\
\text { Attainment value } \\
\text { Utility value } \\
\text { Intrinsic value } \\
\text { Self-efficacy }\end{array}$ \\
\hline Roca and Gagné (2008) & e-Learning & $\begin{array}{l}\text { Perceived usefulness } \\
\text { Perceived ease of use } \\
\text { Perceived playfulness }\end{array}$ \\
\hline Vatanasombut et al. (2008) & Online banking & $\begin{array}{l}\text { Trust } \\
\text { Relationship commitment }\end{array}$ \\
\hline Chen et al. (2009) & Self-service technology & $\begin{array}{l}\text { Satisfaction } \\
\text { Subjective norm } \\
\text { Perceived behavioral control } \\
\text { Optimism }\end{array}$ \\
\hline Lee (2010) & e-Learning & $\begin{array}{l}\text { Satisfaction } \\
\text { Perceived usefulness } \\
\text { Subjective norm } \\
\text { Perceived behavior control } \\
\text { Attitude } \\
\text { Concentration }\end{array}$ \\
\hline Chou et al. (2010) & Online communities & $\begin{array}{l}\text { Performance expectancy } \\
\text { Perceived identity verification } \\
\text { Satisfaction }\end{array}$ \\
\hline Fang and Chiu (2010) & $\begin{array}{l}\text { Online communities of } \\
\text { practice }\end{array}$ & $\begin{array}{l}\text { Altruism } \\
\text { Conscientiousness }\end{array}$ \\
\hline Kim (2011) & Social networking services & Perceived usefulness \\
\hline
\end{tabular}


Lin (2011)

Al-Maghrabi et al. (2011)

Venkatesh et al. (2012)

Zhou et al. (2012)

Wang et al. (2012)

Chen et al. (2012)

Chang and Zhu (2012)

Chong (2013)

Shiau and Luo (2013)

Tang et al. (2014)

Basak and Calisir (2015)

Lehto and Oinas-Kukkonen

(2015)

Gao et al. (2015)
e-Learning

Online shopping

e-Government technologies

Social virtual world services

Instant messaging

Web 2.0

Social networking sites

Mobile commerce

Blogging

Blogging

Facebook

Behavior change support systems

Mobile purchase
Perceived enjoyment

Interpersonal influence

Media influence

Attitude

Satisfaction

Perceived usefulness

Enjoyment

Subjective norm

Attitude

Perceived usefulness

Effort expectancy

Trust

Satisfaction

Affective commitment

Calculated commitment (negative)

Perceived usefulness

Satisfaction

Satisfaction

e-Word-of-mouth

Subjective norm

Self-image

Critical mass

Perceived bridging social capital

Satisfaction

Perceived ease of use

Perceived usefulness

Satisfaction

Perceived enjoyment

Trust

Perceived cost

Perceived enjoyment

Satisfaction

User involvement

Satisfaction

Perceived usefulness

Experiential learning

Attitude

Satisfaction

Perceived credibility

Perceived social support

Perceived effectiveness

Trust

Flow

Satisfaction

\section{Methodology}

As the nature of our study is exploratory and the aim is to build a new theoretical framework, a qualitative methodology based on in-depth interviews was considered as the most appropriate approach (Denzin and Lincoln, 1994; Glaser and Strauss, 1967). The indepth interview method was adopted as it can yield a deeper understanding of the participants' perceptions (Creswell, 2007) about smartphones and their repurchase intention. 
This method will further shed light on consumers' underlying motives, perceptions, experiences, and attitudes toward smartphone repurchase intention in the Chinese smartphone market (Kvale, 2008).

As it is nearly impossible to investigate all categories of adopters, we focused on early adopters of technologies in this study because early adopters have strong influence on other consumers' adoption decisions (Rogers, 2003), particularly in a collectivist society such as China (Hofstede, 1984). China is a country that scores high in the power distance index (Hofstede, 1984), which means that Chinese people tend to trust, respect, and follow leader figures because they represent a form of authority (Kindle, 1985; Yau, 1988). Thus Chinese people are more likely to be influenced in their purchasing by opinion leaders than their counterparts in Western societies (Yau, 1988).

The interview guideline was pilot tested with 6 early adopters of smartphone aged 18 to 25 years old and coming from different parts of China. The translation of pilot interview results was sampled and checked independently by a native Chinese speaker with professional qualifications in English and further cross-checked by another Chinese speaker with similar qualifications.

Following the pilot test, the purposive sampling method was adopted to recruit early adopters of new smartphone models among Chinese students studying in a university in the United Kingdom (UK). We chose this sample group because university students are considered as early adopters of mobile phones (Leung and Wei, 1999; Vishwanath and Goldhaber, 2003) and the importance of young people as a target group in the mobile phone industry is widely acknowledged. Nokia, for instance, first tested new innovations such as the digital camera among young customers (Wilska, 2003). In order to take into account the influence of price and income levels on consumer decision making (Karjaluoto et al., 2005), participants with different family income levels, as shown in Table 3, were contacted: from 
low (5 participants with family income lower than 10,000 Renminbi (Chinese currency, RMB) per month), medium (11 participants with family income between 10,000 and 20,000 RMB), high (12 participants with income over 20,000 RMB), to very high income levels (2 participants with family income over 40,000 RMB). Moreover, an equal number of female and male participants were selected to control potential gender differences (14 females vs. 16 males).

A total of 30 face-to-face interviews were conducted over six months, mainly in Mandarin Chinese. Most of the themes identified in this study emerged in the first 24 interviews; however, we decided to conduct an additional 6 interviews to determine if variations in the interpretation of the phenomenon would offer new opportunities for theorization (Patton, 2002). Interview questions primarily explored experience and use of smartphone, and reasons for adoption, continued use, and repurchase intentions. The total number of interviews was judged as sufficient for reaching theoretical saturation as additional interviews added no new insight (Kvale, 2008; Strauss and Corbin, 1998).

The semi-structured interviews lasted from 40 to 55 minutes and were recorded digitally, transcribed, and translated into English by one research assistant who was a native Chinese speaker, owned a Ph.D. and was familiar with interviewing techniques and qualitative research methods. The participants’ profile is displayed in Table 3.

Table 3. Participants’ profile

\begin{tabular}{llllll}
\hline Code & $\begin{array}{l}\text { Age } \\
\text { group }\end{array}$ & Gender & $\begin{array}{l}\text { Education } \\
\text { level }\end{array}$ & $\begin{array}{l}\text { Area from } \\
\text { China }\end{array}$ & $\begin{array}{l}\text { Family monthly } \\
\text { income (in RMB) }\end{array}$ \\
\hline P1 & $23-25$ & Male & Postgraduate & South & $10,000-20,000$ \\
P2 & $23-25$ & Male & Postgraduate & South & $>20,000$ \\
P3 & $23-25$ & Male & Undergraduate & North & $10,000-20,000$ \\
P4 & $26-30$ & Female & Postgraduate & South & $<10,000$ \\
P5 & $23-25$ & Male & Undergraduate & North-West & $<10,000$ \\
P6 & $23-25$ & Male & Postgraduate & South & $<10,000$ \\
P7 & $26-30$ & Male & Postgraduate & Hong Kong & $>20,000$ \\
P8 & $23-25$ & Female & Postgraduate & South & $>20,000$ \\
P9 & $23-25$ & Female & Postgraduate & South & $10,000-20,000$
\end{tabular}




\begin{tabular}{llllll} 
P10 & $18-22$ & Male & Postgraduate & South & $>20,000$ \\
P11 & $18-22$ & Female & Postgraduate & South & $>20,000$ \\
P12 & $18-22$ & Female & Postgraduate & North & $10,000-20,000$ \\
P13 & $18-22$ & Female & Undergraduate & South & $>20,000$ \\
P14 & $18-22$ & Female & Undergraduate & South & $10,000-20,000$ \\
P15 & $18-22$ & Male & Postgraduate & South & $>20,000$ \\
P16 & $18-22$ & Male & Postgraduate & South & $<10,000$ \\
P17 & $18-22$ & Female & Undergraduate & South & 10,000 to 20,000 \\
P18 & $18-22$ & Female & Postgraduate & South & $>20,000$ \\
P19 & $18-22$ & Male & Undergraduate & South & $>40,000$ \\
P20 & $23-25$ & Female & Postgraduate & South & $>20,000$ \\
P21 & $23-25$ & Male & Postgraduate & North & $10,000-20,000$ \\
P22 & $23-25$ & Female & Postgraduate & North & $10,000-20,000$ \\
P23 & $23-25$ & Male & Postgraduate & South & $>40,000$ \\
P24 & $23-25$ & Male & Postgraduate & North & $10,000-20,000$ \\
P25 & $23-25$ & Female & Postgraduate & North & $<10,000$ \\
P26 & $23-25$ & Male & Undergraduate & North & $>20,000$ \\
P27 & $23-25$ & Female & Undergraduate & North & $10,000-20,000$ \\
P28 & $23-25$ & Female & Postgraduate & North & $>20,000$ \\
P29 & $23-25$ & Male & Postgraduate & North & $>20,000$ \\
P30 & $26-30$ & Male & Postgraduate & South & $10,000-20,000$ \\
\hline
\end{tabular}

For data analysis, open and axial coding techniques were adopted (Strauss and Corbin, 1998). Open coding was used to shed light on the properties and dimensions of concepts in transcripts. Axial coding was used for relating concepts/categories to each other and in turn identifying higher levels categories (Strauss and Corbin, 1998). More specifically, analysis of the data involved identification and classification of themes with a view to elicit the adoption, use and repurchase intention for smartphone brands. While some of the codes were theory driven, others were data driven, as in previous scholarly works (Fereday and Muir-Cochrane, 2006; Dey et al., 2013). For instance, based on the current literature on Chinese culture, $a$ priori codes such as 'product design appeal', and 'enhancing, maintaining and saving mianzi/face' were created. On the other hand, the codes like 'popularity of the brand', 'exclusivity of the brand' that emerged from the data analysis were contrasted with existing academic literature. Hence, the analysis moved back and forth between theories and data. In order to ensure coding consistency, three Ph.D. students and two academics from different disciplinary areas (e.g. marketing, management, information systems, and sociology) who did 
not participate in the research project were contacted to examine the codes produced. This triangulation technique ensured credibility by reducing bias and manual errors, as suggested by relevant literature (Haring, 2008). Some changes were subsequently made to help achieve an agreed interpretation of findings.

\section{Findings}

In contrast to existing technology-driven models, our findings identified various factors that could be insightful to both the IT and marketing literatures to explain Chinese consumers' repurchase intentions. More specifically, the data analysis of interviews showed that factors explaining repurchase intentions include: aesthetic and utilitarian product-related factors such as design appeal, perceived usefulness of unique features; socio-cultural factors such as reference groups' influence (or subjective norm), and mianzi/face considerations; brand-related constructs such as brand popularity, brand's country-of-origin, perceived brand quality, and brand loyalty. The data analysis also highlighted the central role of enhancing, maintaining and saving mianzi or face (cultural factor) in the emerging theoretical framework as shown in Figure 1.

\subsection{Aesthetic and utilitarian product-related factors}

\subsubsection{Design appeal}

Product design is defined as the number of elements chosen and blended into a whole by the design team to achieve a particular sensory effect (Bloch, 1995). The concept of product aesthetic appeal emerged in this study refers to the perceived attractiveness of a smartphone design based on the evaluation of elements such as shape, colors, size, and materials. It differs from Cyr and colleagues' notion of 'image appeal', which is defined as "the extent to which images on the web site are perceived as appropriate and aligned to user expectations, 
satisfying, or interesting” (Cyr et al., 2009, p. 540). Their concept of image appeal is mostly pertaining to all images on the website (product specific or images of humans), specifically in virtual contexts (e.g. website design, mobile commerce) (Cyr et al., 2006; Cyr, 2008; Cyr et al., 2009; Cyr et al., 2010; Cyr, 2013).

Based on our findings, aesthetically pleasing designs affected consumers' repurchase intention of smartphones. More specifically, a smartphone had to please the eyes and product design was one of the most important selection criteria for young Chinese early adopters. Participants specifically referred to four key aspects of a smartphone’s design: screen size, color, shape, and materials. Regarding aesthetics, participants revealed that an 'ugly smartphone' exhibits a lack of style and that, despite people's diverse aesthetic preferences, a smartphone should have an attractive design.

The first eyesight of a product is the appearance, so the design of a phone is particularly important, and the appearance and design of the phone should be consistent with my own image and personality (P10)

I particularly liked the design... it is simple and classy (P14)

[Smartphone Brand Name] is cheaper than other brands, but it is not very popular in China. Then many Chinese prefer using larger screen to play games or watch videos, which made me want to switch to [Smartphone Brand Name]. I also liked the color and design of [Smartphone Brand Name]... the color range attracted me a lot (P28)

Moreover, keeping up with the latest smartphone designs seems to be strictly related to being fashionable. A 'good looking' smartphone is also considered as symbolic of their being very fashion-conscious and as an object that can help distinguish themselves and enhance their mianzi. Therefore, in order to follow the change and fashion trends, young Chinese early adopters are willing to repurchase stylish and innovative smartphones that enable them to feel fashionable and trendy, and in turn enhance their social position in front of others.

...the fashion design and high price can help me enhance mianzi in front of others.... Other people may judge you and your taste according to the smartphone you own (P25) 


\subsubsection{Usefulness of unique features and applications}

Another functional factor that would influence young Chinese early adopters' repurchase intentions of a smartphone was the usefulness and uniqueness of its features and applications (apps). Participants articulated the concept of usefulness together with the uniqueness of the 'apps' available in different smartphone models, which affected their repurchase intention. In terms of specific apps, interviewees declared that 'social apps' such as social gaming and communication apps such as Wechat, QQ, Q Zone, Sina Weibo are the most useful. This finding was in line with a recent McKinsey survey revealing that the country has by far the world's most active social media population (Chiu et al., 2013). Other popular features deemed to be particularly useful included the photo camera, the photo editing apps, and the GPS.

I have recently purchased [Smartphone Brand Operating System]...while with other smartphones some applications and software are to be downloaded from some website and there you can get viruses... while the [Smartphone Brand Name] will rarely get viruses. Therefore I decided to continue to use a higher quality and safer smartphone (P3)

Of course, the app store offers [Smartphone Brand Name] users the best apps' selection, from games, education to entertainment, social networking and so much more. All of the apps are from trusted sources and easy to access, easy to search, and easy to install (P20)

Besides, [Smartphone Brand Name] has the highest quality lenses... you can use this function to do the selfie. There are some apps for photo editing, like the selfie photo editor... (P22)

\subsection{Socio-cultural factors}

\subsubsection{Mianzi or face}

One of central themes that our findings discovered was that buying a specific smartphone brand or model could enable young Chinese early adopters to enhance, maintain or save face in their social relations.

According to interviewees, purchasing an expensive and trendy smartphone enabled them to gain mianzi, which means making them feel special, proud and honored (accepted and recognized) by others. Owning a fashionable, expensive, and/or well-reputed smartphone 
brand fostered emotions and feelings of pride, dignity and vanity in Chinese consumers and led them to believe that they could enhance mianzi, which is a function of their social status. Therefore, participants felt that a well-regarded smartphone brands could help them gain more mianzi.

...if I am not going to use that kind of smartphone, I could feel upset and this may lead to isolation, and if I'm the only one who is not using it, I would feel a sense of inferiority...using an expensive Smartphone is a symbol of following the fashion, and it can help to show to others that I am special and I will feel proud of myself (P1)

If I own a [Smartphone Brand Name], it won't make me lose face, and it fulfills my little vanity and makes my temperament outstanding as well. However, if everyone has a [Smartphone Brand Name] while I have not, I would feel upset and not proud of myself (P13)

By contrast, purchasing a cheap, local or unpopular smartphone, not used in the consumer's social circle, would be a risky decision because it could lead to losing mianzi, experiencing social withdrawal, or feeling inferior in front of others. Interviewees clearly stated that they would feel embarrassed and humiliated in front of others if they were using a cheap, unpopular smartphone brand; owning an unpopular Chinese manufacturer's brand was associated with a lack of style as the majority of Chinese manufacturers were perceived to be lacking innovativeness and style. While a brand with international reputation could project positive images, a 'local' brand might yield negative perceptions, which could cause loss of mianzi.

I cannot allow myself to be looked down upon by others, and want to keep up with the majorities to be fashionable... I am accustomed to the brand and the operating system, and I want to purchase it [the brand] again. However, if the one I had used brought me bad impression, I will change my purchase intention ... (P8)

I would definitely feel that I am losing face if I own a Chinese brand. In my case, all of my classmates were from wealthy background... As I remember no one of my college friends was using... [Local Brand Name]. Most of them were using [International Smartphone Brand Name] (P21)

[International Smartphone Brand Name] as a large international brand can help gain more mianzi than a Chinese local smartphone brand... I will definitely choose a large international brand in order to gain more mianzi (P28) 
However, I will not consider local brands because some brands only follow or copy [International Smartphone Brand Name]. The brand image and reputation of some local brand is bad, also the users' experience is not good, and the design is poor... if I'll be using these brands it will make me lose face (P29)

\subsubsection{Subjective norm}

TRA and TPB suggest that normative (or social) influences from reference groups, such as peers, friends, or parents, shape one's intentions toward a given behavior. Normative influences are represented using the subjective norm construct, defined as the degree to which individuals believe that people who are important to them think they should perform the behavior in question (Fishbein and Ajzen, 1975).

In line with TRA (Fishbein and Ajzen, 1975) and TPB (Ajzen, 1991), our findings showed that friends and family (reference groups) were indeed a strong influence of consumers' smartphone repurchase intentions. In fact, friends' and family's advice as well as the pressure to conform were so influential that some consumers revealed that they were willing to repurchase the same smartphone as their friends' without collecting much information about the product/model itself. Having the same smartphone model as their friend would enhance consumers' social inclusion as they stated that this would facilitate socialization and their interpersonal relationships (e.g. more topics to discuss such as score at social games) and help them maintain face.

... If I use the same good smartphone as my friends, it would be more comfortable and easier to socialize with them (P1)

In order to get along well with others and make it easier to join them, using the same brand's smartphone can help. For example, if everyone uses the same smartphone brand we can play the same games... I would think that I can download one and play with them together, and find out more common topic with them (P16)

I have considered buying a [Smartphone Model Name]. Unfortunately, my friends told me that [Brand Name] is not as good as [Smartphone Model Name], such as poorer screen resolution, short battery life and they had some problems with the phone (P21) 


\subsection{Brand-related factors}

\subsubsection{Brand popularity}

Based on interview data, young Chinese early adopters tended to choose popular brands. More specifically, the meaning associated with brand popularity emerging here referred to a consumer's assessment of the level of diffusion or popularity of a brand in society or in the consumer's social circles. While we placed brand popularity in brand-related factors, it could also be considered as a cultural notion because its importance may derive from Chinese people's dependence on social norms and group conformity. In Chinese society the social pressure to conform to the group would seemingly 'urge' consumers to make decisions that might not necessarily reflect individuals' private opinion. Consequently, the more people purchase the same brand, the more it becomes popular in society; as brand popularity increases, the risk for consumers to lose face decreases. Thus, brand popularity reduces the risk of losing face and plays an important role in Chinese consumers' repurchase intentions.

Additionally, the association between brand popularity and perceived product quality emerged, i.e. the more popular a brand, the higher its perceived quality.

When I see that many people are using a specific smartphone brand, I know it should be good, otherwise, it won't be so popular (P6)

... if the brand is popular and most people are using it, there should be some reasons... I will think this brand has a good reputation because a lot of people are buying the same brand (P8)

If a brand has a large consumer base, I would consider buying it, as to me popularity stands for reliable and good quality product (P14)

\subsubsection{Brand exclusivity}

The concept of brand exclusivity is first used by Groth and McDaniel (1993) to describe the attainment of "exclusive value" status by a product or service or "the positioning of a brand such that it can command a high price relative to similar products” (Groth and McDaniel, 1993, p. 11). Exclusivity is conceptualized as a pricing strategy to support the marketing of luxury or high-quality products. In fact, in the marketing literature the concept 
of exclusivity is often found together with high price, limited quantities, which are all considered as a characteristic of luxury brands (Nia and Zaichkowsky, 2000). Luxury goods or status goods are defined as those for which the mere use or display of a particular branded product brings prestige to the owner, apart from any functional utility (Grossman and Shapiro, 1988). Those goods are often expensive and exclusive such as Cartier and Rolex watches, Hermes handbags, Gianni Versace suits and Mercedes Benz cars (Nia and Zaichkowsky, 2000).

Interviewees declared that they would feel that they could gain mianzi if they owned a smartphone of high brand exclusivity. Moreover, we found that exclusivity and popularity were inversely related, meaning that when a brand or product became too widespread it would compromise the perceptions of exclusivity linked to the brand.

At first, most users of [Smartphone Brand Name] were affluent people. But it is now becoming more common and many people from the middle class are using it, such as students, officers... However, the price of [Smartphone Brand Name] is the highest in the smartphone market and low-income workers cannot afford it... this makes me feel to have mianzi and good taste (P29)

\subsubsection{Brand's country of origin}

Consumers develop associations, which are often stereotypical, between the products and brands from particular countries and the attributes of those products. Nagashima (1970, p. 68) defines such notion of brand's country of origin as "the image that consumers associate with a given country-of-origin as the picture, the reputation, the stereotype that businessmen and consumers attach to products of a specific country. This image is created by variables such as representative products, national characteristics, economic and political background, history, and traditions.” The country-of-origin image has the power to evoke consumers' belief about product attributes and to influence evaluations of products and brands (Srikatanyoo and Gnoth, 2002). 
From the findings, it appeared that young Chinese early adopters' stereotypical perceptions of the country-of-origin of a smartphone brand would influence their repurchase intentions. However, there was no preference for a specific country, but rather for the international nature of a smartphone brand manufacturer. Evidently, young Chinese consumers tended to repurchase international brands that would convey an image of safety, innovativeness and advanced technology, which also links to perceived product's quality and enables them to maintain or increase mianzi. In other words, a highly reputable international smartphone brand would signal high quality.

I chose a good, international smartphone brand because it stands for high quality and hi-tech design. If the products of brand are not very good then that company cannot gain positive brand image and popularity (P29)

The brand is important to me... using [International Brand Name] can help to increase more mianzi than using...or ... [Chinese Brand Names] (P30)

\subsubsection{Perceived brand quality}

Product perceived quality refers to "the consumer's [subjective] judgment about a product's overall excellence or superiority” (Zeithaml, 1988, p. 3). Personal product experiences, unique needs, and consumption situations may influence the consumer's subjective judgement of quality (Yoo et al., 2000). Zeithaml (1988) identifies perceived quality as a component of brand value; therefore, high perceived quality would drive a consumer to choose a specific brand rather than other competing brands. In line with this view, our participants clearly articulated this concept stating that the perceived quality of a smartphone brand in relation to its durability (of the battery), resistance, performance of the operating system, and safety features, affect their repurchase intentions. Among these quality dimensions, the safety features and operating system performance were most frequently mentioned.

I have recently purchased [Smartphone Brand Operating System]...while with other smartphones some applications and software are to be downloaded from some website and there you can get viruses... while the [Smartphone Brand 
Name] will rarely get viruses. Therefore I decided to continue to use a higher quality and safer smartphone brand (P3)

The materials of [Smartphone Brand Name] are of good quality. It is not easy to be broken; my previous smartphone screen got scratches from my keys when it was in my pocket... On the contrary, [Smartphone Brand Name] has a good quality screen, which is made of resistant materials that can avoid this to happen... After using [Smartphone Brand Name] for a long time, you can tell that the speed of the phone does not slow down. My previous [Smartphone Brand Name] smartphone started to slow down after one year only (P22)

\title{
4.3.5 Brand loyalty
}

Brand loyalty is defined as "a deeply held commitment to rebuy or repatronize a preferred product or service consistently in the future, despite situational influences and marketing efforts having potential to cause switching behavior” (Oliver, 1997, p. 392). Brand loyalty is a component of the customer-based brand equity model, which is also composed of other assets, including perceived quality and brand awareness (Aaker, 1991; Keller, 1993).

Our findings also suggested that brand loyalty had a strong influence on early adopters’ repurchase intentions. Loyalty is mainly derived from a positive evaluation of the brand image and from previous experiences. It is important to note that some smartphone brands enjoyed a higher level of loyalty than others.

\begin{abstract}
Absolutely I have never changed. I trust [Brand Name] products which never let me down. I am a big [Brand Name] fan, actually. I own a [the brand's laptop model], [the brand's music player model], [the brand's tablet model]... (P20) I like all kind of [Brand Name] products which is another important reason for me to choose [Smartphone Brand Model]. If there are a lot of brands to choose, I am sure that I would like to choose [Brand Name] without any hesitation because I like this brand and what it represents (P11)
\end{abstract}

The analysis of these findings further led us to develop a theoretical framework of smartphone repurchase intentions as follows. 


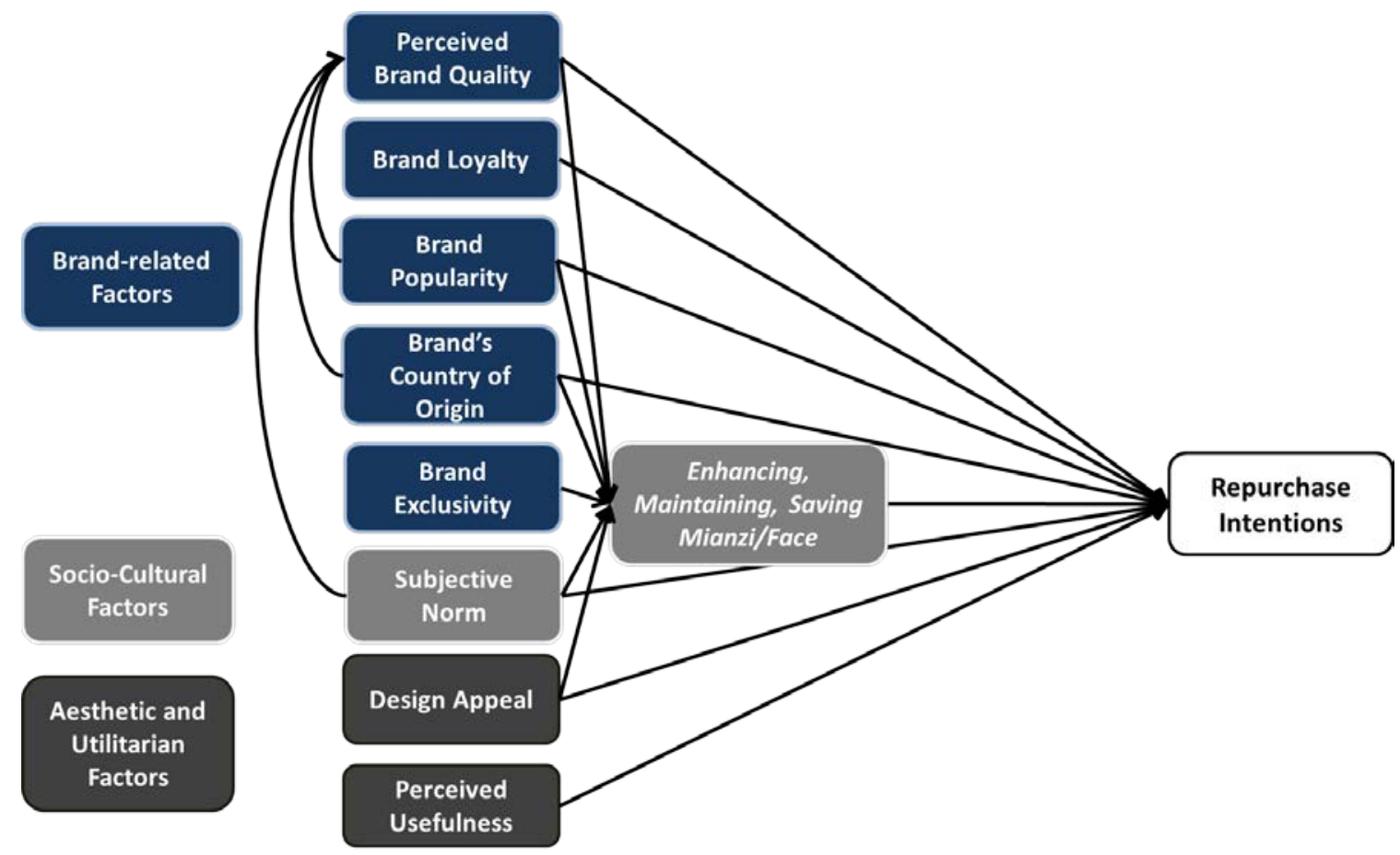

Figure 1. Theoretical framework emerging from the study

\section{Discussion}

As illustrated in Figure 1, consumers' repurchase intentions of smartphones are evidently intertwined with their fashion needs (e.g. aesthetics factors), brand perceptions, cultural values, and utilitarian considerations rather than determined by only expectation-confirmation and technology-based considerations as suggested in the existing literature (e.g. Bhattacherje, 2001). Beyond the existing understanding of technology-driven models, our findings highlight that young Chinese consumers' repurchase intentions are mainly affected by three dimensions of factors: aesthetic and utilitarian product-related factors related to design appeal and perceived usefulness; socio-cultural factors such as friends and family members' influence as well as considerations of enhancing, maintaining and saving mianzi considerations; brand-related factors such as brand popularity, brand's country-of-origin image, perceived brand quality, and brand loyalty. 
Evidently, smartphone repurchase decisions are increasingly determined by various elements, not necessarily related to the beliefs or experiences about a technology, but rather associated with the symbolic and cultural meanings of smartphone brands identified by consumers as well as with the capacity of brands to communicate these meanings to socially significant others. These findings thus increase the existing understanding of post-adoption behaviors.

In accordance with previous results in other contexts, perceived usefulness and subjective norms are also found to be significant for repurchase intentions (e.g. Chen et al., 2009; Lee, 2010; Al-Maghrabi et al., 2011), which re-emphasizes their relevance in different contexts.

\subsection{Aesthetics and utilitarian factors}

Contrary to Karjaluoto et al.'s (2005) findings which suggest that Finnish students' mobile phone purchase decisions are driven by technical issues, our framework illustrates that young Chinese early adopters' repurchase decisions of smartphones are mostly driven by nontechnical considerations. Since a smartphone is considered as a fashion and lifestyle item, Chinese early adopters tend to follow the aesthetic trends to appear fashionable; as such, innovative and trendy design is commonly recognized as an influential factor in their smartphone repurchases. Previous research on visual appeals in the IS literature has predominantly emphasized the influence of website design on trust, usefulness, ease of use, enjoyment, and satisfaction (e.g. Cyr et al., 2006, 2009, 2010; Cyr, 2013). This study stresses the importance of product design appeal (e.g. shape, colors, size, and materials) in influencing Chinese consumers' mianzi and repurchase intentions. The importance of aesthetics emerging in this study thus reinforces the notion that aesthetics play an important role in human appreciation and attitudes toward information technology (Tractinsky, 2004). 
Utilitarian considerations included perceived smartphone brand quality and usefulness of features and applications. This finding is important in that it highlights that specific aspects/features of smartphone brands are particularly important to Chinese consumers. Additionally, these results show the growing interest of Chinese early adopters toward the smartphones' social apps and the performance of the operating system, which represent unique features of smartphone brands and drive repurchase intentions.

\subsection{Socio-cultural constructs}

Our research further identifies and analyzes how young Chinese early adopters' sociocultural dispositions influence their repurchase intentions for smartphones. More specifically, peers' and family's recommendations as well as concerns for enhancing, maintaining and not losing face influence Chinese early adopters' smartphone repurchase intentions. These findings can be explained by Chinese society's collectivist culture, particularly driven by Confucius teachings that focuses on group orientation and interpersonal harmony in managing all interpersonal relations (Hofstede et al., 1997; Brewer and Chen, 2007). As a result, Chinese consumers tend to value group decisions, order, and security in their purchase decisions. Since traditional Chinese culture is rooted in kinship and family bonds, people rely on word-of-mouth communication to obtain credible product information (Yau, 1988). This business and social practice can be related to herd behavior (Sun, 2013) and often urges Chinese consumers to depend on family's and friends' advice and word of mouth. Comparing with previous studies of Western consumers (e.g. Wilska, 2003; Karjaluoto et al., 2005) where a mobile phone symbolizes a part of personal identity by Finnish consumers, this study clearly shows that Chinese consumers' motivations toward repurchase intentions of smartphones are more socially-oriented, in that a smartphone is purchased to fulfill two needs: 
the need for social integration, harmony, and inclusion and the need for enhancing, maintaining, or not losing mianzi.

Face is a peculiar characteristic of Chinese social psychology. This study shows how different factors can contribute to enhancing, maintaining, or saving face/mianzi, which influences consumers' repurchase intentions of smartphones. While the concept of face is a phenomenon that is also present in Western societies, namely the social anchoring of self in the gaze of others, the Chinese experience of face (i.e. mianzi) highlights aspects of face that are less visible in non-Chinese societies (Hwang, 1987; Qi, 2011). In fact, mianzi is a far more complicated concept and it involves fellowship and recognition within a group, endorsement of competencies and skills, emotions and sense of self-esteem (Liao and Bond, 2010; Qi, 2011).

Within a social network, having mianzi enhances not only relative position but also many types of privileges that further improve the quality of life and has much greater social significance among Chinese than do similar notions among Western consumers (Hwang, 1987; Ji and Kang, 2010). A smartphone brand is not only repurchased for what its functionalities can do but, more importantly, to communicate a consumer's social status and wealth. Secondly, for young Chinese consumers an expensive, well designed, and highly reputed international smartphone brand can improve one's mianzi on the one hand, while a cheap, unpopular, unfashionable, outdated smartphone brand can lead to mianzi losses on the other. Hence, a brand's symbolic capacity to enhance mianzi is evidently important for young Chinese early adopters of technology. This finding is particularly interesting because existing technology-driven models rarely emphasize cultural factors and thus may not predict technology use across all cultures (Alhirz and Sajeev, 2015; Hsu et al., 2015). In other words, the cultural factors emerging from our findings can be insightful in explaining technology 
repurchase intentions beyond satisfaction and perceived usefulness that are commonly examined in the existing literature.

\subsection{Brand-related constructs}

The adoption and continuance intention literatures emanating from the IS discipline do not specifically emphasize the role of brand attributes and characteristics in determining consumers' intention to repurchase technological products. Our findings, by contrast, suggest that young Chinese early adopters' repurchase intentions of smartphones are intertwined with their perceptions of the concerned brands. Since iPhone's multi-touch interface model launched in 2007, the global market has been populated by several competing brands such as Samsung, Nokia, BlackBerry, Motorola, Sony, HTC, LG, Xiaomi, ZTE, Lenovo, and Huawei, all offering a similar technology but proposing a different brand experience. This trend can also be recognized in other consumer technologies, such as smart TVs, digital cameras, tablets, and the like. In general, when a new technology is mature, trendy or particularly profitable, competing brands will rapidly enter the market by offering alternative models and/or versions of a technological product. Thus, in such a competitive context, brand perceptions become even more important to consumers.

Moreover, our research further helps advance the understanding of the sources of brand equity (Aaker, 1991) in an Asian context. For example, the concept of brand popularity and the capacity of a brand to enhance, maintain and save mianzi appear to be unique determinants of brand value in such a context. For instance, Chinese people's respect for group orientation, community, solidarity and harmony in society often leads to collective pressures on individuals to choose specific brands that are more popular in a given society at a specific point in time. This behavior can be partially observed in herd behavior that is related to innovation fads and fashions (Abrahamson, 1991; Sun, 2013). More specifically, 
when consumers lack of knowledge about the innovation or there exists high uncertainty in the marketplace, they tend to follow or imitate actions of 'opinion leaders' (Rogers, 2003) or ‘fashion setters' (Abrahamson, 1991). In doing so, consumers observe and follow prior adopters to reduce uncertainty and post-adoption regrets. The construct of brand popularity has received little attention in the marketing literature (Dean, 1999), which tends to refer brand popularity to financial or market share data (Raj, 1985). By contrast, in this study it signifies consumer perception of how widespread a brand in society is. In a collectivist society such as China, this emergent concept might be of particular interest for future research.

Moreover, while the existing literature on brand exclusivity focuses on luxury products such as fashion, jewelries, expensive perfumes and wristwatches (Groth and McDaniel, 1993; Stokburger-Sauer and Teichmann, 2013), our findings show that exclusivity plays a similar effect on Chinese consumers' perceptions of smartphone brands. While smartphones are not generally considered as luxury products because they are not produced in limited quantities, some brands have positioned themselves as more aspirational, prestigious, and luxurious brands. Exclusivity is often communicated through a high price tag. In contrast to Karjaluoto et al. (2005), which findings suggested that price is of vital concern in consumers' mobile phone purchase decisions, most participants in our study revealed that they would not consider price as their repurchase factor. Their price considerations by participants are seemingly suppressed by the need to maintain and improve face, which motivates them to invest heavily on luxury products (or perceived as such) that facilitate conspicuous consumption. In fact, the capacity of the smartphone to enable the individual to gain mianzi or save face appears to be of crucial importance to young Chinese consumers. In other words, the higher the price of a smartphone the higher its capacity to communicate exclusivity and ultimately to enhance the owner's mianzi. 
Hence, technology adoption models for consumer electronics such as smartphones should take brand-related factors into account. As existing technology-driven models and IS scholars (Sun, 2013; Koo et al., 2015; Song et al., 2015) have not incorporated brand-related constructs, and the marketing literature has also failed to bridge between the two disciplinary perspectives, this paper makes a significant contribution to the field by combining and applying multi-disciplinary concepts in the Chinese consumer context.

\section{Managerial implications}

This research can be particularly important for R\&D and marketing managers of smartphone companies because it provides insights into Chinese consumers' repurchase intentions. Our findings highlight that Chinese consumers' repurchase decisions are mainly driven by branding, socio-cultural, aesthetics and utilitarian considerations. The insights gained through this study can help develop better marketing strategies and smartphone models that are adapted to suit the Chinese cultural context. More specifically, the results suggest that, to be accepted in the Chinese market, developers of smartphone and technological devices should place a stronger emphasis on understanding the meanings associated with a brand and its reputation. Since the brand and lifestyle associations are important to young Chinese early adopters of technology, an effective marketing strategy would be to create unique associations that enhance greater differentiation from other smartphone brands.

Culturally, as Chinese people tend to rely strongly on word of mouth and early adopters are known to act as opinion leaders, which help reach a critical mass of technology users (Rogers, 2003), smartphone companies can further consider focusing their marketing strategies on early adopters to foster repurchase intention. In China, the world's most active social media population (Chiu et al., 2013), early adopters are mostly young and eager users 
of social media; they can be targeted in those platforms with appropriate messages, promotions, and badge schemes (as reward for their contribution), and ideally, turned into fans to spread the word to their circles. Therefore, to maximize the power of social media and electronic word of mouth from early adopters and opinion leaders, smartphone manufacturers should take proactive measures to identify these consumers and interact with them on various social media platforms (e.g. Wechat, Q Zone, Sina Weibo).

Furthermore, as the smartphone design and appearance is of great importance to Chinese consumers, we recommend smartphone manufacturers to experiment with more innovative and fashionable designs to satisfy early adopters' needs for exclusivity. An effective strategy would be to partner with popular fashion designers to develop aesthetic features inspired by a brand collection or a fashion theme. This strategy could work well particularly because Chinese early adopters evidently prefer certain exclusive smartphone brands for their aspirational, exclusive, and luxurious images.

As Chinese consumers frequently repurchase emerging smartphone models, it is imperative for smartphone manufacturers to accelerate the pace of innovation so that they can remain competitive in the Chinese market. For example, for the current leading smartphone companies to maintain their market shares in China, they should continuously accelerate the pace of innovation for their products and apps, and at the same time maintain their exclusive branding strategy that seems to be particularly appealing to Chinese early adopters of technology. For competing international brands, they may need to consider leveraging marketing strategies to enhance their brand image and at the same time improving their products and launching innovative and exclusive smartphone models ahead of competitors.

Furthermore, most Chinese brands hold a negative brand image to the point that they may cause face loss to its adopters, which is a serious derogation of personal integrity in Chinese culture. We therefore suggest Chinese companies to start investing more on marketing their 
brand image, for example, through the use of advertising and specific celebrity endorsers that resonate well with young early adopters. As innovation may not be limited to technological features, style and aesthetical development aligned with exclusive fashion brands may be one possible source of innovation for their future consideration.

Additionally, consumers seem to be particularly interested in the usefulness and uniqueness of applications. It is thus recommended that smartphone companies invest more in apps development and acquisition because such strategy can make their smartphones being perceived more attractive to consumers.

Finally, due to the notion of mianzi or face, Chinese consumers perceive price as a secondary factor for repurchase decisions. Thus, we recommend that leading smartphone manufacturers, that are perceived as exclusive brands, do not sacrifice brand image/exclusivity for affordable pricing strategies.

\section{Limitations and future research}

While our findings and implications have accomplished the study's research purposes, some limitations may need further attention. Firstly, a qualitative methodology lacks of generalizability that quantitative measures provide. Insights gained here can thus merely present a deeper understanding of smartphones phenomenon in Chinese markets rather than imply a confirmatory generalization to all consumer behaviors. Secondly, only early adopters of smartphones among young, Chinese consumers who studied in the UK were selected in the investigation. Their perspectives and experiences may not represent all Chinese consumers.

Future research could thus examine the factors affecting repurchase decision among different segments of the population, such as adult and elderly consumers. In addition, different methodologies can be considered for examining the same research phenomenon so that deeper and/or broader implications can be reached. For example, a large scale 
quantitative study that tests our emerging framework among Chinese or other Asian consumers, who share cultural similarities with China (e.g. Confucianism), would be insightful. A comparative analysis with Western consumers could further validate the model across cultures. If researchers decide to do so, they should adapt the model to the specific cultural context investigated. For instance, mianzi is a concept that is peculiar to Chinese culture. In other contexts other cultural concepts may explain consumer repurchase intentions of smartphone brands. For instance, in individualist countries constructs like self-image or need for uniqueness could be more important in explaining early adopters' repurchase intentions because in these countries the 'individual' as opposed to the group is more important to consumers (Hofstede, 1980).

Potentially, our emerging framework can also be tested for different technologies simultaneously. For instance, smartphones are considered as conspicuously consumed products. Differences about consumers' adoption behaviors or repurchase intentions might emerge between conspicuously consumed and privately consumed technological products. It can be argued that mianzi and face considerations might be less important when a technological product is consumed at home.

Moreover, as the importance of brand equity and the concept of culture have been emphasized, future studies of repurchase intentions can consider a more holistic approach that integrates theories from different disciplines to better explain continuance adoption behaviors. These theories should go beyond technology-driven models (e.g. TAM, IDT, TPB, and UTAUT) and consider brand equity (Aaker, 1990) and social-cultural perspectives. In doing so, a more comprehensive understanding of repurchase intentions and adoption behaviors across different markets and cultural contexts can be achieved. 


\section{References}

Aaker, D.A. (1991), Managing Brand Equity: Capitalizing on the Value of a Brand Name, Free Press, New York.

Abrahamson, E. (1991), "Managerial fads and fashions: The diffusion and rejection of innovations", Academy of Management Review, Vol. 16 No. 3, pp. 586-612.

Ajzen, I. (1991), "The theory of planned behavior", Organizational Behavior and Human Decision Processes, Vol. 50 No. 2, pp. 179-211.

Alhirz, H., and Sajeev, A.S.M. (2015), "Do cultural dimensions differentiate ERP acceptance? A study in the context of Saudi Arabia”, Information Technology \& People, Vol. 28 No. 1, pp. 163-194.

Al-Maghrabi, T., Dennis, C., and Vaux Halliday, S. (2011), “Antecedents of continuance intentions towards e-shopping: the case of Saudi Arabia”, Journal of Enterprise Information Management, Vol. 24 No. 1, pp. 85-111.

Bao, Y., Zhou, K.Z.Z. and Su, C. (2003), "Face consciousness and risk aversion: Do they affect consumer decision-making?” Psychology \& Marketing, Vol. 20 No. 8, pp. 733755.

Basak, E., and Calisir, F. (2015), “An empirical study on factors affecting continuance intention of using Facebook”, Computers in Human Behavior, Vol. 48 July 2015, pp. 181-189.

Bhattacherjee, A. (2001), "Understanding information systems continuance: an expectation confirmation model”, MIS Quarterly, Vol. 25 No. 3, pp. 351-370.

Bloch, P.H. (1995), "Seeking the ideal form: Product design and consumer response", Journal of Marketing, Vol. 59 No. 3, pp. 16-29.

Brewer, M.B. and Chen, Y.R. (2007), "Where (who) are collectives in collectivism? Toward conceptual clarification of individualism and collectivism”, Psychological Review, Vol. 114 No. 1, pp. 133-151.

Chang, Y. P., \& Zhu, D. H. (2012), “The role of perceived social capital and flow experience in building users' continuance intention to social networking sites in China", Computers in Human Behavior, Vol. 28 No. 3, pp. 995-1001.

Chen, J. and Kim, S.Y. (2013), “A comparison of Chinese consumers' intentions to purchase luxury fashion brands for self-use and for gifts", Journal of International Consumer Marketing, Vol. 25 No. 1, pp. 29-44.

Chen, S.C., Chen, H.H. and Chen, M.F. (2009), "Determinants of satisfaction and continuance intention towards self-service technologies", Industrial Management \& Data Systems, Vol. 109 No. 9, pp. 1248-63.

Chen, S.-C., Yen, D.C. and Hwang, M.I. (2012), "Factors influencing the continuance intention to the usage of Web 2.0: An empirical study", Computers in Human Behavior, Vol. 28 No. 3, pp. 933-941.

Chiu, C. M., and Wang, E. T. (2008), "Understanding Web-based learning continuance intention: The role of subjective task value", Information \& Management, Vol. 45 No. 3, pp. 194-201.

Chiu, C., Lin, D. and Silverman, A. (2013), "High Influence: China’s Social Media BoomIconsumer: Life Online Compendium", http://www.mckinseyonmarketingandsales.com/high-influence-chinas-socialmediaboom (accessed 10 February 2014).

Chiu, C.-M., Chiu, C.-S. and Chang, H.-C. (2007), "Examining the integrated influence of fairness and quality on learners' satisfaction and web-based learning continuance intention”, Information Systems Journal, Vol. 17 No. 3, pp. 271-87. 
Chong, Y.-L.A. (2013), "Understanding mobile commerce continuance intentions: An empirical analysis of Chinese consumers," Journal of Computer Information Systems, Vol. 53 No.4, pp. 22-30.

Chou, S.-W., Min, H.-T., Chang, Y.-C. and Lin, C.-T. (2010), "Understanding continuance intention of knowledge creation using extended expectation-confirmation theory: An empirical study of Taiwan and China online communities”, Behaviour \& Information Technology, Vol. 29 No. 6, pp. 557-70.

Creswell, J.W. (2007), Qualitative Inquiry and Research Design: Choosing among Five Approaches, SAGE, London.

Crockett, D. and Wallendorf, M. (2004), “The role of normative political ideology in consumer behaviour”, Journal of Consumer Research, Vol. 31 (December), pp. 51129.

Cyr, D. (2008), "Modeling web site design across cultures: relationships to trust, satisfaction, and e-loyalty”. Journal of Management Information Systems, Vol. 24 No. 4, pp. 4772.

Cyr, D. (2013). "Website design, trust and culture: An eight country investigation”, Electronic Commerce Research and Applications, Vol. 12 No. 6, pp. 373-385.

Cyr, D., Head, M. and Ivanov, A. (2006), "Design aesthetics leading to m-loyalty in mobile commerce”. Information \& Management, Vol. 43 No. 8, pp. 950-963.

Cyr, D., Head, M. and Larios, H. (2010), "Colour appeal in website design within and across cultures: A multi-method evaluation”, International Journal of Human-Computer Studies, Vol. 68 No. 1, pp.1-21.

Cyr, D., Head, M., Larios, H. and Pan, B. (2009), "Exploring human images in website design: a multi-method approach”. MIS Quarterly, Vol. 33 No. 3, pp. 539-566.

Davis, F.D. (1989), "Perceived usefulness, perceived ease of use, and user acceptance of Information Technology”, MIS Quarterly, Vol. 13 No. 3, pp. 318-40.

Dean, D.H. (1999), "Brand endorsement, popularity, and event sponsorship as advertising cues affecting consumer pre-purchase attitudes”, Journal of Advertising, Vol. 28 No. 3, pp. 1-12.

Denzin, N.K. and Lincoln, Y.S. (1994), Handbook of Qualitative Research, Sage, London.

Dey B., Binsardi A., Prendergast R., and Saren M. (2013), "A qualitative enquiry into the appropriation of mobile telephony at the Bottom of the Pyramid", International Marketing Review, Vol. 30 No. 4, pp. 297-322.

eMarketer. (2015a), Asia-Pacific Boasts More Than 1 Billion Smartphone Users. http://www.emarketer.com/Article/Asia-Pacific-Boasts-More-Than-1-BillionSmartphone-Users/1012984\#sthash.jfgvBKh8.dpuf (accessed March 11 2016).

eMarketer. (2015b), 2 Billion Consumers Worldwide to Get Smart(Phones) by 2016 - over Half of Mobile Phone Users Globally Will Have Smartphones in 2018. http://www.emarketer.com/Article/2-Billion-Consumers-Worldwide-Smartphones-by2016/1011694\#sthash.CYFmjzTM.dpuf (accessed June 15 2015).

Fang, T. (1999), Chinese Business Negotiating Style, SAGE, Thousand Oaks, California.

Fang, Y.-H., and Chiu, C.-M. (2010), "In justice we trust: Exploring knowledge-sharing continuance intentions in virtual communities of practice", Computers in Human Behavior, Vol. 26 No. 2, pp. 235-246.

Fereday, J. and Muir-Cochrane, E. (2006), "Demonstrating rigour using thematic analysis: a hybrid approach of inductive and deductive coding and thematic development", International Journal of Qualitative Methods, Vol. 5 No. 1, pp. 1-11.

Fishbein, M. and Ajzen, I. (1975), Belief, Attitude, Intention and Behavior: An Introduction to Theory and Research, Addison-Wesley, Reading, MA. 
Gao, L., Waechter, K. A., \& Bai, X. (2015), “Understanding consumers' continuance intention towards mobile purchase: A theoretical framework and empirical study-A case of China”, Computers in Human Behavior, Vol. 53 December 2015, pp. 249-262.

Glaser, B.G. and Strauss, A. (1967), The Discovery of Grounded Theory: Strategies for Qualitative Research, Aldine Publishing Company, Hawthorne, NY.

Grossman, G.M. and Shapiro, C. (1988), "Foreign counterfeiting of status goods", The Quarterly Journal of Economics, February, pp. 79-100.

Groth, J.C. and McDaniel, S.W. (1993), "The exclusive value principle: the basis for prestige pricing”, Journal of Consumer Marketing, Vol.10 No.1, pp. 10-16.

Haring, R. (2008), "Commentary: Conducting culturally appropriate qualitative market research in the native American landscape", Qualitative Market Research: An International Journal, Vol. 11 No.1, pp. 7-16.

Ho, D.Y.F. (1976), “On the Concept of Face”, American Journal of Sociology, Vol. 81 No. 4, pp. 867-884.

Hofstede, G., (1980). "Motivation, leadership, and organization: do American theories apply abroad?” Organizational dynamics, Vol. 9 No. 1, pp.42-63.

Hofstede, G. (1984), "The cultural relativity of the quality of life concept", Academy of Management Review, Vol. 9 No. 3, pp. 389-398.

Hofstede, G., Hofstede, G. J., and Minkov, M. (1997). Cultures and Organizations. New York, NY: McGraw Hill.

Hsu, M. H., Tien, S. W., Lin, H. C., and Chang, C. M. (2015), "Understanding the roles of cultural differences and socio-economic status in social media continuance intention," Information Technology \& People, Vol. 28 No. 1, pp. 224-241.

Hu, H.C. (1944), “The Chinese Concept of Face”, American Anthropologist, Vol. 46 No. 1, pp. 45-64.

Hwang, K.-K. (1987), "Face and Favor: The Chinese Power Game”, American Journal of Sociology, Vol. 92 No. 4, pp. 944-974.

Ji, B. and Kang, J.H. (2010), "Face or subjective norm? Chinese college students' purchase behaviour toward foreign jeans”, Clothing and Textile Research Journal, Vol. 28 No.3, pp. 218-233.

Joo, J. and Sang, Y. (2013), “Exploring Koreans' smartphone usage: An integrated model of the technology acceptance model and uses and gratifications theory", Computers in Human Behavior, Vol. 29 No. 6, pp. 2512-2518.

Karjaluoto, H., Karvonen, J., Kesti, M., Koivumäki, T., Manninen, M., Pakola, J., Ristola, A. and Salo, J. (2005), "Factors affecting consumer choice of mobile phones: Two studies from Finland”, Journal of Euromarketing, Vol. 14 No. 3, pp. 59-81.

Keller, K.L. (1993), "Conceptualizing, measuring, and managing customer-based brand equity”, Journal of Marketing, Vol. 57 No. 1, pp. 1-22.

Kim, B. (2011), "Understanding antecedents of continuance intention in social-networking services”, CyberPsychology, Behavior \& Social Networking, Vol. 14 No. 4, pp. 199205.

Kim, D., Chun, H. and Lee, H. (2014), "Determining the factors that influence college students' adoption of smartphones”, Journal of the Association for Information Science and Technology, Vol. 65 No. 3, pp. 578-588.

Kindle, T. (1985), Chinese Consumer Behaviour: Historical Perspective Plus an Update on Communication Hypotheses, in Sheth, J. and Tan, C.T. (Eds.), Historical Perspectives of Consumer Behaviour, National University of Singapore and Association for Consumer Behaviour, Singapore, pp. 186-190.

King, Y.K. (1993), Chinese Society and Culture, Oxford University Press, Hong Kong. 
Koo, C., Chung, N., Kim, H.-W. (2015), "Examining explorative and exploitative uses of smartphones: a user competence perspective”, Information Technology \& People, Vol. 28 No. 1, pp.133-162.

Kozinets, R. V. (2002), "The field behind the screen: using netnography for marketing research in online communities”, Journal of Marketing Research, Vol. 39 No.1, pp. 6172.

Kvale, S. (2008), Doing Interviews, Sage, London.

Le Monkhouse, L., Barnes, B.R. and Stephan, U. (2012), "The influence of face and group orientation on the perception of luxury goods: A four market study of East Asian consumers”, International Marketing Review, Vol. 29 No. 6, pp. 647-72.

Lee, C. (1990), "Modifying an American consumer behavior model for consumers in Confucian culture: The case of Fishbein behavioral intention model”, Journal of International Consumer Marketing, Vol. 3 No.1, pp. 27-50.

Lee, D., Pae, J.H. and Wong, Y.H. (2001), “A model of close business relationships in China (guanxi)”, European Journal of Marketing, Vol. 35 No. 1/2, pp. 51-69.

Lee, M.-C. (2010), "Explaining and predicting users' continuance intention toward eLearning: An extension of the expectation-confirmation model”, Computers \& Education, Vol. 54 No. 2, pp. 506-16.

Lehto, T., and Oinas-Kukkonen, H. (2015), "Explaining and predicting perceived effectiveness and use continuance intention of a behaviour change support system for weight loss”, Behaviour \& Information Technology, Vol. 34 No. 2, pp. 176-189.

Leung, L., and Wei, R.A.N. (1999), "Who are the mobile phone have-nots? Influences and consequences", New Media and Society, Vol. 1 No. 2, pp. 209-226.

Leung, T.K.P., and Chan, R.W. (2003), "Face, favour and positioning-a Chinese power game”, European Journal of Marketing, Vol. 37 No. 11/12, pp. 1575-1598.

Liao, C., Chen, J.-L., and Yen, D. C. (2007), "Theory of planning behavior (TPB) and customer satisfaction in the continued use of e-service: An integrated model”, Computers in Human Behavior, Vol. 23 No. 6, pp. 2804-2822.

Liao, Y. and Bond, M.H. (2010), "The dynamics of face loss following interpersonal harm for Chinese and Americans”, Journal of Cross Cultural Psychology, Vol. 20 No. 10, pp. 1-14

Limayem, M., Hirt, S. G., and Cheung, C. M. K. (2007), "How habit limits the predictive power of intention: The case of information systems continuance”, MIS Quarterly, Vol. 31 No. 4, pp. 705-737.

Lin, C., Wu, S. and Tsai, R. (2005), "Integrating perceived playfulness into expectation confirmation model for web portal context”, Information \& Management, Vol. 42 No. 5, pp. 683-93.

Lin, K. M. (2011), “e-Learning continuance intention: Moderating effects of user e-learning experience”, Computers \& Education, Vol. 56 No. 2, pp. 515-526.

Nagashima, A. (1970), “A comparison of Japanese and US attitudes toward foreign products”, Journal of Marketing, Vol. 34 No. 1, pp. 68-74.

Nia, A., \& Lynne Zaichkowsky, J. (2000), "Do counterfeits devalue the ownership of luxury brands?” Journal of Product \& Brand Management, Vol. 9 No. 7, pp. 485-497.

Nielsen (2014), How Smartphones Are Changing Consumers' Daily Routines around the Globe. $\quad$ http://www.nielsen.com/us/en/insights/news/2014/how-smartphonesarechanging-consumers-daily-routines-around-the-globe.html (accessed March 10 2014).

Oliver R. L. (1997). Satisfaction: A Behavioral Perspective on the Consumer, IrwinMcGraw-Hill, New York, NY. 
Oliver, R. L. (1980), “A cognitive model of the antecedents and consequences of satisfaction decisions”, Journal of Marketing Research, Vol XVII, pp. 460-469.

Oliver, R. L. (1993), "Cognitive, affective, and attribute bases of the satisfaction response", Journal of Consumer Research, Vol. 20 No.3, pp. 418-430.

Oliver, R. L. (1999), “Whence consumer loyalty?” The Journal of Marketing, Vol. 63, pp. 33-44.

Park, Y. and Chen, J.V. (2007), “Acceptance and adoption of the innovative use of smartphone”, Industrial Management \& Data Systems, Vol. 107 No. 9, pp. 1349-1365.

Patton, M.Q. (2002), Qualitative Research and Evaluation Methods, $3^{\text {rd }}$ ed., Sage, Thousand Oaks, CA.

Persaud, A., and Azhar, I. (2012), "Innovative mobile marketing via smartphones: Are consumers ready?” Marketing Intelligence \& Planning, Vol. 30 No. 4, pp. 418 - 443.

Qi, X. (2011), “Face A Chinese concept in a global sociology”, Journal of Sociology, Vol. 47 No. 3, pp. 279-295.

Raj, S. P. (1985), "Striking a balance between brand "popularity" and brand loyalty," The Journal of Marketing, Vol. 49 No. 1, pp. 53-59.

Roca, J. C., Chiu, C. M., and Martínez, F. J. (2006), "Understanding e-learning continuance intention: An extension of the Technology Acceptance Model”, International Journal of Human-Computer Studies, Vol. 64 No. 8, pp. 683-696.

Roca, J.C. and Gagné, M. (2008), "Understanding e-learning continuance intention in the workplace: A self-determination theory perspective", Computers in Human Behavior, Vol. 24 No. 4, pp. 1585-604.

Rogers, E.M. (2003), Diffusions of Innovations, 5th Ed, Free Press, New York, NY.

Shiau, W.-L. and Luo, M.M. (2013), "Continuance intention of blog users: The impact of perceived enjoyment, habit, user involvement and blogging time”, Behaviour \& Information Technology, Vol. 32 No.6, pp. 570-83.

Song, J., Swang, S., Drennan, J. and Andrews, L. (2015), "Same but different? Mobile technology adoption in China”, Information Technology \& People, Vol. 28 No. 1, pp. 107-132.

Srikatanyoo, N. and Gnoth, J. (2002), "Country image and international tertiary education”, Journal of Brand Management, Vol. 10 No. 2, pp. 139-48.

Stokburger-Sauer, N. E. and Teichmann, K. (2013), "Is luxury just a female thing? The role of gender in luxury brand consumption”, Journal of Business Research, Vol. 66 No. 7, pp. 889-896.

Strauss, A. and Corbin, J. (1998), Basics of Qualitative Research: Techniques and Procedures for Developing Grounded Theory, 2nd Ed. Sage, Thousand Oaks, CA.

Sun, H. (2013), “A longitudinal study of herd behavior in the adoption and continued use of technology”, MIS Quarterly, Vol. 37 No. 4, pp. 1013-1041.

Tang, J.-t.E., Tang, T.-I. and Chiang, C.-H. (2014), "Blog learning: Effects of users' usefulness and efficiency towards continuance intention", Behaviour \& Information Technology, Vol. 33 No. 1, pp. 36-50.

Tian, K. and Belk, R. W. (2005), "Extended self and possessions in the workplace”, Journal of Consumer Research, Vol. 32 September, pp. 297-310.

Tractinsky, N. (2004), "Toward the study of aesthetics in information technology", Proceedings of Twenty-Fifth International Conference on Information Systems, pp. 1120.

Vatanasombut, B., Igbaria, M., Stylianou, A. C., and Rodgers, W. (2008), "Information systems continuance intention of web-based applications customers: The case of online banking”, Information \& Management, Vol. 45 No. 7, pp. 419-428. 
Venkatesh, V. and Zhang, X. (2010), “Unified theory of acceptance and use of technology: U.S. vs China”, Journal of Global Information Technology Management, Vol.13 No.1, pp. 5-27.

Venkatesh, V., Chan, F. K., and Thong, J. Y. (2012), Designing e-government services: Key service attributes and citizens' preference structures. Journal of Operations Management, Vol. 30 No. 1, pp. 116-133.

Vishwanath, A. and Goldhaber, G.M. (2003), "An examination of the factors contributing to adoption decisions among late diffused technology products", New Media and Society, Vol. 5 No. 4, pp. 547-572.

Wang, W., Ngai, E.W.T. and Wei, H. (2012), "Explaining instant messaging continuance intention: The role of personality", International Journal of Human-Computer Interaction, Vol. 28 No. 8, pp. 500-10.

Wilska, T.A. (2003), "Mobile phone use as part of young people's consumption styles”, Journal of Consumer Policy, Vol. 26 No. 4, pp. 441-463.

Yau, O.H.M. (1988), “Chinese cultural values: Their dimensions and marketing implications”, European Journal of Marketing, Vol. 22 No. 5, pp. 44-57.

Yoo, B., Donthu, N., and Lee, S. (2000), "An examination of selected marketing mix elements and brand equity", Journal of the Academy of Marketing Science, Vol. 28 No. 2, pp. 195-211.

Zeithaml, V. A. (1988), "Consumer perceptions of price, quality, and value: a means-end model and synthesis of evidence", The Journal of Marketing, Vol. 52 No. 3, pp. 2-22.

Zhou, Z., Fang, Y., Vogel, D. R., Jin, X. L., \& Zhang, X. (2012), “Attracted to or locked in? Predicting continuance intention in social virtual world services", Journal of Management Information Systems, Vol. 29 No. 1, pp. 273-306. 